\title{
The Controversy of Views About Health Service Quality Between Health Provider and Patients With Bpjs Insurance:A Case Study in Mamami Hospital - Kupang
}

\author{
Frans Salesman ${ }^{1}$, Abdul Rohim Tualeka ${ }^{2} \&$ Maria Domingga Bolilera ${ }^{3}$ \\ ${ }^{1}$ Institute of Health Science, Citra Husada Mandiri, Kupang, Indonesia \\ ${ }^{2}$ Faculty of Public Health Ailanggga University, Surabaya, Indonesia \\ ${ }^{3}$ Students of Postgraduate Nusa Cendana University, Kupang, Indonesia \\ Correspondence: Frans Salesman, Institute of Health Science, Citra Husada Mandiri, Kupang, Indonesia. E-mail: \\ franssalesman@gmail.com
}

Received: June 5, 2018 Accepted: July 24, 2018 Online Published: August 1, 2018

doi:10.5539/gjhs.v10n9p18 URL: https://doi.org/10.5539/gjhs.v10n9p18

\begin{abstract}
Background: The latest challenge of hospital service system in Indonesia now adays is the controversy of views about health service quality between health provider with patients andfamilies. Patients as the ultimate assessors measure the quality from medical care started up to the patients get cured without any physical defect. Mean while, the health providers as the health suppliers see the quality of health service from the using of medical scientific standard up to the curing of sickness.

Purpose: The paper analyzes the controversy of health service quality between the Providers and patients in Mamami Hospitaluse BPJS (Badan Penyelenggara JaminanSosial) as a Social Insurance Administration Bureau in Indonesia.

Methods: Observational survey with cross sectional. Independent variables: sympathy and empathy, interaction, environment quality. Dependent variable: health service quality. Variables measurement: Likert scale. Population and sample: BPJS inpatient for 3 days in Mamami hospital. Sample number: 200 respondents taken with purposive sampling.

Result: The three independent variables effect health service quality. Significant point of sympathy and empathy ( $\beta=490 ; \alpha=0.00)$; environment quality $(\beta=180 ; \alpha=0.48)$; interaction with patients $(\beta=233 ; \alpha=0.18)$.

Conclusion: Controversy of viewseliminated in modern health service system. Mixed service between medical care and cognitive service is the answer. The providers come in and get inpatient service in the room for patients with psychological deficiency. The mixed of service have impacts in the change of patients' status: from consumers to customers. The resultant for health service institutions is profitability.
\end{abstract}

Keywords: health quality, medical care, psychological deficiency, health

\section{Introduction}

The new challenge in hospital health service system in Indonesia now adays is the remaining difference in the view of health service quality between health providers with patients and their families. In the concept of health service quality perception, patients are seen as the ultimate assessors. The quality of health service has a strong connection with psychological satisfaction of consumers and establish the good image of any health service product. The impact is in the decision of the patients or their families; whether they want to get only that one-time-treatment or become the customers of that hospital. Patients will become customers if they are satisfied with the result of the service given; whether the result is going accordingly or near to the expectation they had before came or got inpatient care in the hospital. Mean while, according to providers, quality perception is the consistency of medical care procedure operational standard application according to medical scientific principles.

As a commodity, the concept of health service quality has six characteristics: performance, durability, feature, reliability, consistency, and design (Ana Syaketi \& Suadrwati, 2010). Quality measurement when used in measuring health service should have four criteria: (1) Physical facilities including buildings and supporting 
facilities for Local Government Clinic (Puskesmas) or Hospital; (2) presentation and availability of staffs; (3) supervise; and (4) Basic medication precision (Ana Syaketi\&Suadrwati, 2010).

Mamami hospital - Kupang was built in 2004. Later, according to Decision Letter from the Head of East Nusa Tenggara Health Department No: Yanmed.233/442.A/VII/2008, on $18^{\text {th }}$ July, 2008 the state of the Hospital with specialty for Mother and Children, was changed into General Hospital Type-D is ranking of hospital organization status accordingIndonesian health ministry regulation, with health service segment is to low income civilians. High income patients usually get their treatment in Siloam hospital and Prof.Dr. W.Z. Johannes General Hospital.Mamami hospital with Kartini Hospital, Leona Hospital, and Dedari Hospital accept patients who are enlisted in BPJS. Although the marketing segmentation is for low income patients, the management of the hospital always try to improve the quality of the services given to either inpatients or outpatients, through the application of medication procedure according to Procedure Operational Standard of medical service. All the patients admitted to Mamami hospital are the members of BPJS (BadanPenyelanggara Jaminan Sosial) isa bureau that manages health insurance in Indonesia for low income people. However, during 2017, the number of patients significantly decreased.

Between January to December 2017 the number of patients enlisted as BPJS members were 4.832. the highest number of patients admitted in was in April 2017: 354 patients and the lowest was in August: 252 patients (Mamami Hospital Director, 2018). The fluctuation affected the income and profitability of the hospital. In short term this will affect the fluency of cash paid for health service operational activities, salary for medical expert, sub-expert, paramedics, and other staffs. Compare to the number of patients with BPJS who get admitted to other private hospitals in Kupang, Mamami's are low. The decline is caused by variables of different views of health service quality between providers with BPJS' patients will be used as the pupose of research.

\section{Methods}

The research is observational survey with cross sectional design (Notoatmodjo, 2005). Research population are patients enlisted in BPJS insurance with inpatient status. The research used purposive sampling with number of samples 200 respondents. Inclusive criteria of the samples are willing to be interviewed and had been cared as inpatients more than 3 days. Research period is February to March 2018. Independent variables: (1) sympathy and empathy; (2) interaction between providers with patients; (3) quality of hospital' physical environment. Dependent variables: assessment of health service quality.

Both independent and dependent variables are measured using Lickert Scale: (1) sympathy and empathy, measurements: very empathy and friendly: if providers behave with great hospitality toward patients' complaints within $<5$ minutes respond time; empathy and friendly: if providers friendly respond toward patients' complaints within 5- 7 minutes respond time; quite friendly and empathy: if providers quite friendly when respond to patients' complaints within 8-10 minutes respond time; less friendly and empathy: if providers with less friendly attitude respond to patients' complaints within 11 - 13 minutes respond time; and not friendly and empathy: if providers with not-friendly attitude respond to patients' complaints within > 14 minutes respond time; (2) Quality of interaction, measurements: very good: if the interaction uses local language; good: if the interaction uses both Indonesianand local language; quite good: if the interaction uses Indonesian languagewith some symbols; less good: if the interaction uses Bahasa Indonesia; bad: if there is no interaction at all; (3) Quality of physical environment is measured from the aspects of the cleanliness of inpatient rooms and water closed, exposure, and torpidity. Very good: if inpatient rooms and water closed are clean, good exposure, no torpidity; good: if only three are fulfilled: quite good: if only two are fulfilled; less good: if only one is fulfilled; and bad: if none is fulfilled. Independent variables: the quality of health service measured from the combination of patients' healing and providers' cognitive behavior during medical care. Very good: if during the medical care period, patients get a very good sympathy, empathy and interaction, with clean environment until patients are healed without any physical defect; good: if during the medical care period, patients get a good sympathy, empathy and interaction, with clean environment until patients are healed with one week rehab;quite good: if during the medical care period, patients get a quite good sympathy, empathy and interaction, with quite clean environment until patients are healed weeks two weeks rehab;less good: if during the medical care period, patients get a less good sympathy, empathy and interaction, with less clean environment until patients are healed with three weeks rehab; bad: if during the medical care period, patients not get any sympathy, empathy and interaction, with dirty environment until patients are healed but with permanent defect. Information from respondents were recorded through questioners.

Data are analyzed using Linear Regression. Respondents' characteristics are: educational grade, respondents' work, and respondents' income. 


\section{Findings}

\subsection{Respondents' Characteristics}

Respondents' characteristics are categorized according to: gender (Figure 1); education (Figure 2); work (Figure 3); and income (Figure 4).

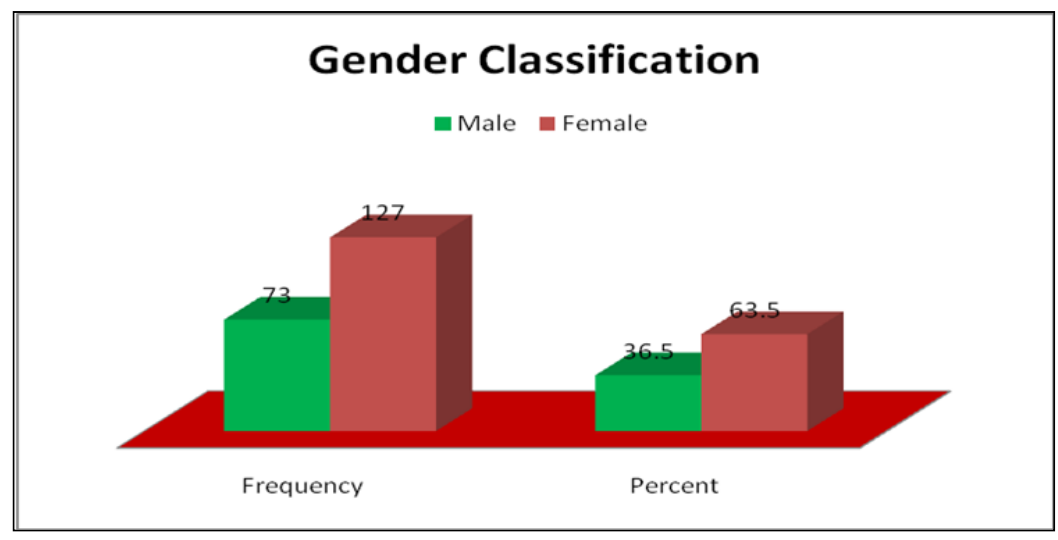

Figure 1. Gender Classification

Source: Research Result

Figure 1 describes that male respondents are 127 (63.50\%) and female respondents are 73 (36.50\%). Educational grades are described in Figure 2 below.

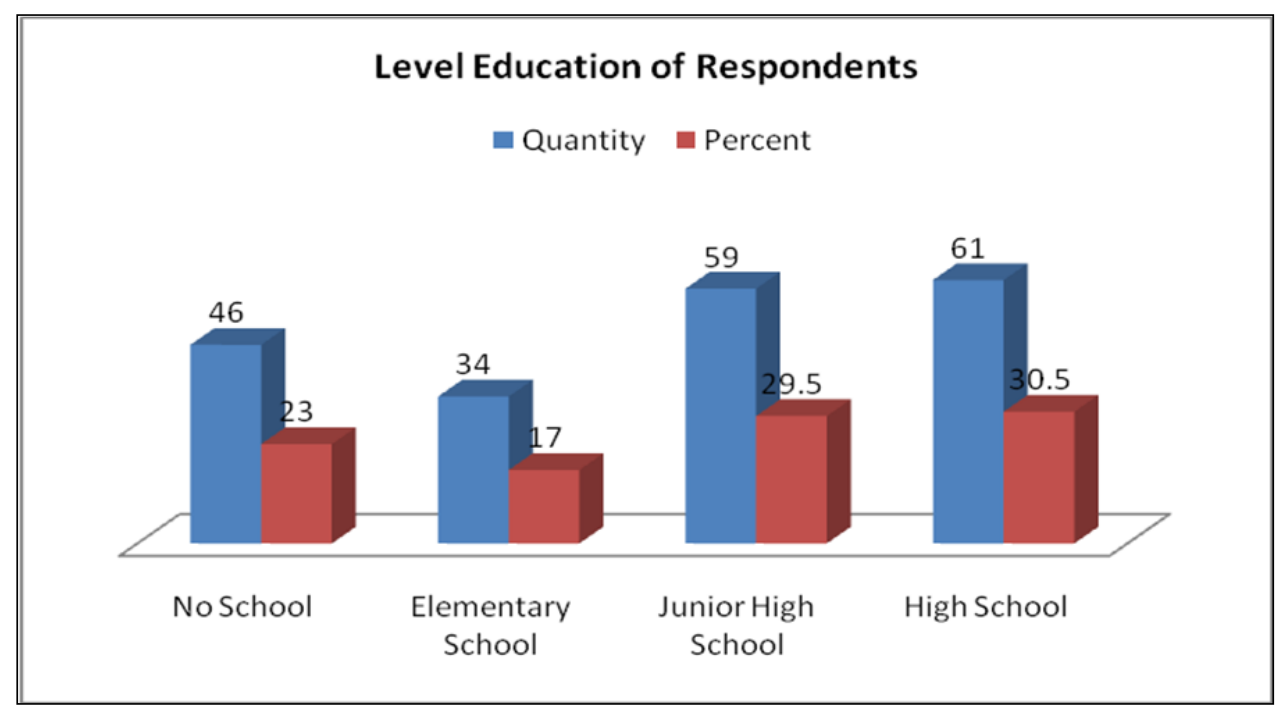

Figure 2. Level Education Respondents

Source: Research Result

Un educated respondents are 46 respondents (23\%),who completed elementary school are 34respondents (17\%), who completed Junior High School are 59 respondents $(29.50 \%)$ who completed Senior High School are 61 Respondents' (30.50\%) works are described in Figure 3 below. 


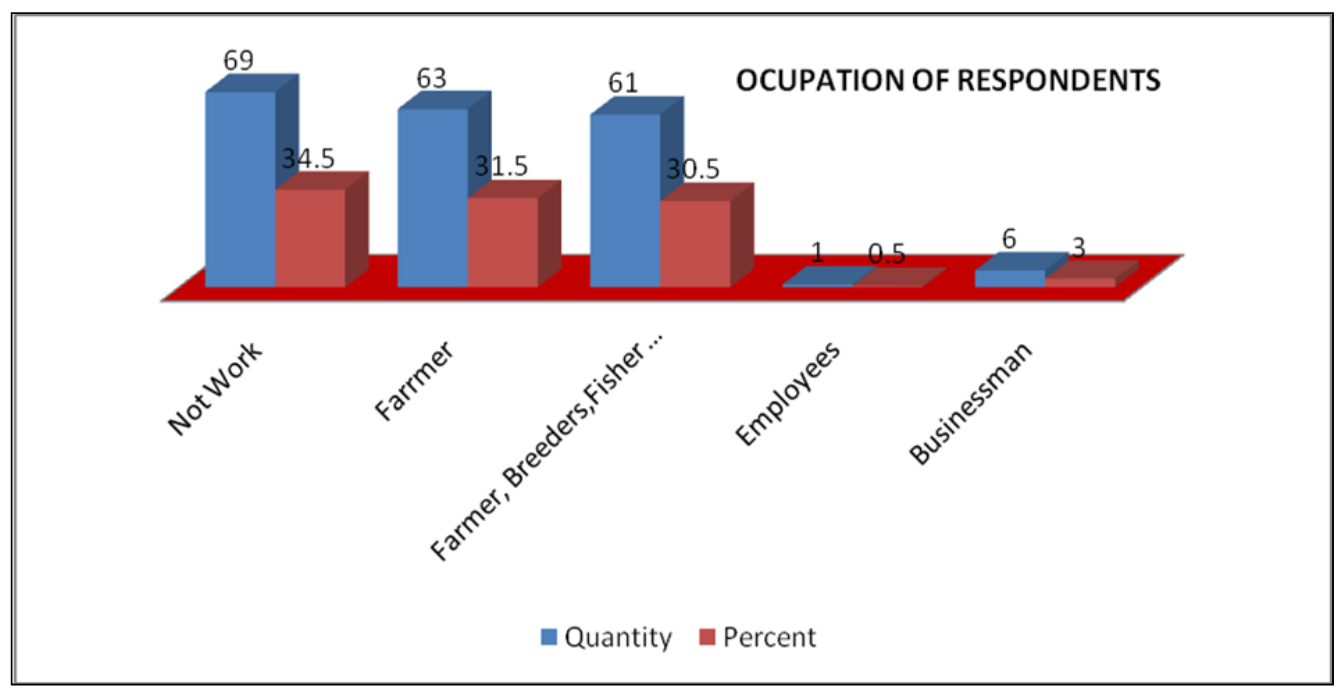

Figure 3.Ocupation of Respondents

Source: Research Result

Figure 3 shows that unemployed respondents are 69 (34.50\%), 63 (31.50\%) farmers, 61 (30.50\%) farmers who also work as breeders and fishermen, $1(0.5 \%)$ civil officer, $6(3 \%)$ businessmen. Respondents' income is shown in Figure 4 below.

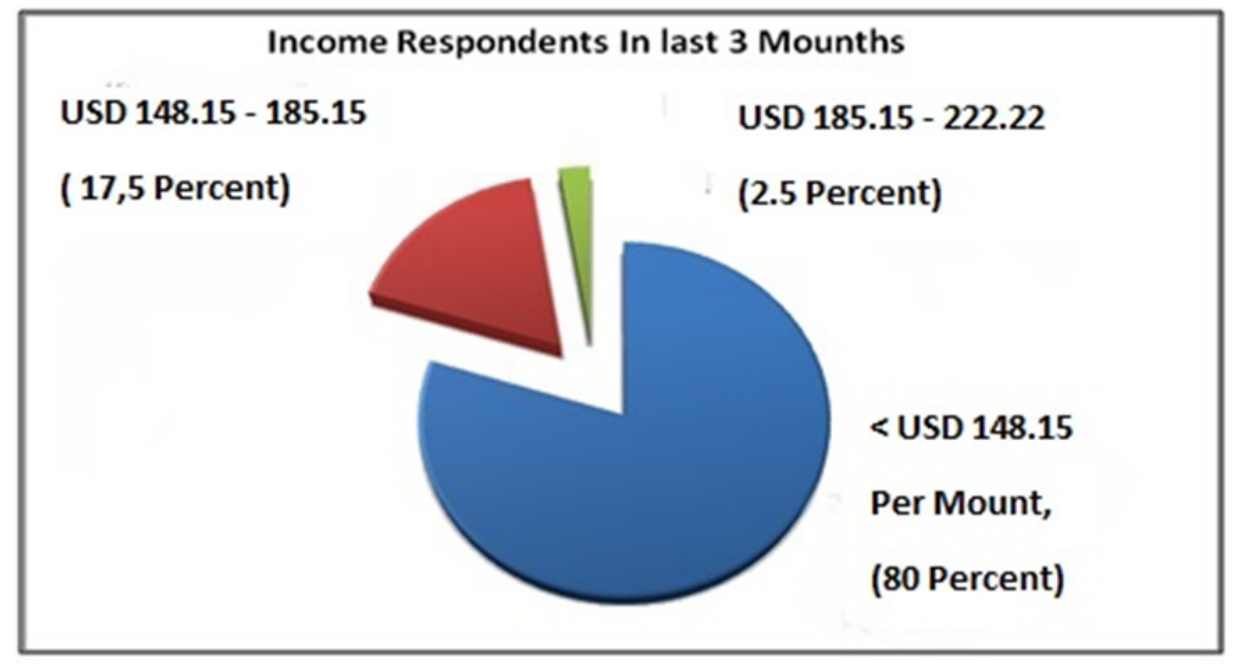

Figure 4. Income Respondents In Last 3 Months

Source: Research Result

Figure 4 shows that 160 persons ( $80 \%$ ) have income < USD 148,15 per month, 35 persons (17.50\%) have income USD 148,16-185.15, and 5 persons (2.5\%) have income USD 185.15-222.22. The respondent's income is below the average per capita income in East Nusa Tenggara Province of USD 521 per year.

\subsection{Regression Analyzes}

The result of linear regression analyzes in Table 1 states that all three independent variables affect patients' healing quality with significance points: sympathy and empathy $(\beta=490 ; \alpha=0.00)$; environment quality $(\beta=180 ; \alpha=$ $0.48)$; interaction with patients $(\beta=233 ; \alpha=0.18)$. See at Table 1 below: 
Table 1. Influence Sympathy \& Empathy, Enviromental Quality, and Interaction with Patient to Quality of Healing at Hospital MamamiKupang 2017

\begin{tabular}{lllllll}
\hline \multirow{2}{*}{ Model } & \multicolumn{2}{l}{ Unstandardized Coefficients } & & Standardized Coefficients & T & Sig. \\
\cline { 2 - 3 } & B & Std. Error & & 2.158 & .032 \\
\hline (Constant) & .364 & .169 & .471 & 6.743 & .000 \\
Sympathy \& Empathy & .490 & .073 & .171 & 1.986 & .048 \\
Enviromental Quality & .180 & .090 & .224 & 2.387 & .018 \\
\hline Interaction With Patient & .233 & .098 & &
\end{tabular}

a. Dependent Variable:Quality of Healing.

Source: Research Result.

\section{Discussion}

\subsection{Sympathy and Empathy and Quality of Healing}

Sympathy is agreeing with or approve someone's feelings, such as happy, sad, sorrow, exciting, and so on. Empathy is a mental situation where someone identifies himself/herself in the patients' feelings and act according to the need and desires of the patients (Isusilaningtyas, 2012). In the study published by Journal of the Royal Society of Medicine, Jeffrey shows three technical terms used by doctors to show their support for the patients; those are: empathy, sympathy, and pity. According to Jeffrey, doctors should show more empathy, sympathy and pity toward their patients (Bestari, 2016)). Patients' need of medical care not only in diagnoses, therapy, and medication, but also on medical care diversification by adding psychological approaches, where a health officer enter and stay in the room for patients with psychological deficiency (Salesman, 2001).

The ideal is contemporary medical care approach should leave behind the old paradigm that patients only need to get cured through the medication process. A comprehensive understanding about predisposition condition of culture, social, and economy of any patient become an integral part of today's medical care. A medical officer must be equipped with the knowledge of anthropology, economy, and sociology of the society where he/se is stated so that with the psychological flexibility they can easily become part of patients' lives. Without this, a health officer will be abandoned bypatients.

In special case, a patient who medically referred from any first-grade facility will meet a doctor with medical monoculture service, might not come back to the doctor for any medical treatment. They just becomes a first and last consumer. Normatively speaking, all patients should become customers in order to bring long-term profitability for the hospital. From the result of this research, there is a significant impact from sympathy and empathy toward healing quality assessment of the patients with BPJS insurance in Mamami hospital - Kupang. ( $\beta$ $=490 ; \alpha=0.00)$; environment quality $(\beta=180 ; \alpha=0.48)$; interaction with patients $(\beta=233 ; \alpha=0.18)$. these variables dominantly affect the healing quality assessment.

\subsection{Interaction Provider with Patient and Quality of Healing}

According to Harnack\& Fest, interaction is a communication process as a process of interaction between people to reach the objective of intrapersonal and interpersonal integration (Dilani, 2009). In the context of medical care, content of interaction among doctors, paramedics, and patients is the condition of patients' helath status after getting medication during inpatient period in Mamami hospital. The interaction pattern needs to be built in two ways so that patients could feel that medical officer really pays attention towards his/her suffering. Language and the ethic of dialogue become important in the interaction. Patients who come from traditional culture with less medical terms might not understand the messages from the doctors. For that, medical officers need to have an interpreter who can deliver the message with local language of the patients. When a medical officer interacts with communication pattern that is not accordingly with the values and norms of interaction of patient's culture, there will be an assessment of the patient that the medical officer does not infiltrate to the communication pattern of the patients. Sometimes, the message is interpreted in the wrong way by the patients. From the result if interviews with patients of BPJS insurance in Mamami hospital - Kupang it states that they do not really understand doctors' message, because it was uttered in Indonesia language without translating into local language. They only try to follow doctors' and nurses' gestures when visited them. This is supported by statistic analyzes that shows impacts of interaction between providers and patients with the assessment of health service quality in Mamami hospital Kupang ( $\beta=233 ; \alpha=0.18$ ).Rahmania, $\mathrm{P}$ in her research in Makmur Jaya Clinic in Ciputat - Tangerang - Banten 
finds that cognitive communication pattern from doctors to patients uses symbols to get the same medical meaning of the messages with the patients (Rahmania, 2011).

\subsection{Environment Quality and Quality of Healing}

According to the BPJS Insurance policy, member who pays regular monthly fee USD 1.85 or who gets dotation get treatment in class 3 inpatient rooms. In each of those rooms there are more patients than in class 2 and class 1, that is 4 to 6 persons. Other than patients who get donations, all class 3 patients can move to higher class. For that, the patients or families should sign a declaration letter. In the letter, patients should state that it is his will to move to other class with agreement from the families; and with that they agree to pay the additional treatment caused by the movement (Ana Syaketi \& Suadrwati, 2010). Patients with BPJS insurance who come from low income family will find it difficult to move up. The cleanliness and calmness of inpatient rooms depend solely on the number of patients. Mamami hospital - Kupang serves patients with BPJS insurance from Kupang City and District of Kupang who have predisposition of Timor Culture; patients will be looked after by many family members. Imagined, if in a class 3 room there are $4-6$ patients looked after by 3 family members of each patient then there are $12-18$ persons in class 3 inpatient room with only one water closed and one bathroom.

Perception of environment quality according to patients and families, based on their traditional living back in their villages, assesses that there is impact of environment quality upon health service quality in Mamami hospital Kupang ( $\beta=180 ; \alpha=0.48)$. Nevertheless, the perception of environment quality is different from medical officer point of view. Sometimes, the difference brings friction between medical officer with patients' families. It occurs frequently when inpatient rooms are cleaned by cleaning service or when doctors visit patients. If patients are cosumers, then, ideally, their wishes and needs should be met by providers (Rahmania, 2011).

All health facilities should be interpreted as medical-technical environment which orient in physical and medical need. Health facilities not only meant for reducing sickness risk. Strategy to calm the patients down and make them feel relax often neglected. Moreover, psychology, social, and spiritual needs of the patients are neglected in the design of health facility and put aside in the philosophy of caring (Pratinadina, 2011).

\section{Conclusion}

Difference of view between health officer with patients about health service quality still occur until now. Provider sees quality as in applying of medical scientific standard until patients are healed without any additional rehabilitation. Meanwhile, according to patients with BPJS insurance see health service quality in Mamami hospital Kupang as the combination of service from medical care process with sympathy and empathy, local culture-based interaction, quality of hospital environment until the patients are healed without any physical defect. Providers could come in and stay in the rooms for patients with psychological deficiency.

These additional servicesare precious suggestions for health service management in the future so that patients will not become one-time consumer but customers who regularly visit the health service. If patients ask for continuous health service in a health service institution, then the resultant for health service institutions is a long-term profitability.

\section{Acknowledgements}

We want to thank the Director of Mamami Hospital - Kupang and Head of Kupang City Health Department who had entrusted us with the research about the controversy of views about health service quality between health provider and partients with BPJS insurance; a case study in Mamami Hospital - Kupang. We also thank Chief Director of Post Graduate Program of Nusa Cendana University, Head of the Civil Health Study Program, Head of Statistic Body of East Nusa Tenggara, Head of Health Department of East Nusa Tenggara Province wo have provided data, documents, and information for the researcher in order to finish the paper.

\section{Competing Interests Statement}

The authors declare that there are no competing or potential conflicts of interest.

\section{References}

Ana Syaketi, W. N., \& Suadrwati, Y. (2010). Analyzes of Social Insurance Administration Organization (BPJS); Transformation of State-Owned Enterprises for Social Insurance). Jurnal Ekonomi \& Kebijakan Publik, 1(1) 1-24. Retrieved from http://jurnal.dpr,go,id/index.php/article/view/72/39

Bestari, L. (2016). This is Why a Doctor Has to Show Empathy for The Patients. Retrieved $2^{\text {nd }}$ June, 2018, from http://intisari.grid.id/.../inilah-alasan-mengapa-dokter-harus-menunjukka...

BPJS Kesehatan. (2016). An Explanation about Care Unit for Each BPJS Insurance's Classes. Retrieved $2^{\text {nd }}$ June, 
2018, from https://www.panduanbpjs.com

Dilani, A. (2009). Psychosocially Supportive Design - Scandinavian Healthcare Design. In R. Del Nord, (ed.), The Culture for the Future of Healthcare Architecture. Journal of RUAS, 12(2). 13 Proceedings of the 28th, International Public Health Seminar, Alinea Editrice.

Isusilaningtyas, E. (2012). Sympathy and Empathy. Retrieved 2nd June, 2018, from http://berandapsikologi.blogspot.com/2012/09/simpati-dan-empati.html

Mamami Hospital Director. (2018). Managerial Report of Mamami Hospital in 2017 (pp. 156-177).

Muninjaya, G. A. A. (2011). Quality Management of Health Service(pp. 123). Jakarta: EGC.

Notoatmodjo, S. (2005). Methodology of Health Research. Retrieved from http://www.ibrary.um.ac.id/ free.../koleksi-digital-perpustakaan-23012.html

Pakar Komunikasi.com (2017). Social Communication According to Experts. Retrieved $2^{\text {nd }}$ June, 2018, from https://pakarkomunikasi.com

Pratinadina, L. (2011). Customers' Satisfaction. Retrieved 1st June, 2018, from https://pratidinalestiyani.wordpress.com/2011/05/05/mutu-pelayanan/...

Rahmania, P. (2011). Communication Pattern of Doctors toward Patients. In the Process of Healing in Makmur Jaya Clinic (pp. 99).

Salesman, F. (2001). Demand of Mother and Child Health Service in Ethnics of Manggarai, Bajo, and Bima (A Dissertation for Doctorate Degreein Post Graduate Program of Airlangga University, Surabaya - East Java, pp. 235-239).

\section{Copyrights}

Copyright for this article is retained by the author(s), with first publication rights granted to the journal.

This is an open-access article distributed under the terms and conditions of the Creative Commons Attribution license (http://creativecommons.org/licenses/by/4.0/). 